University of Nebraska - Lincoln

DigitalCommons@University of Nebraska - Lincoln

2000

Fitness costs of resistance to Bacillus thuringiensis in the Indianmeal moth, Plodia interpunctella

\author{
Brenda Oppert \\ USDA-ARS, bso@ksu.edu \\ Richard Hammel \\ USDA-ARS \\ James E. Throne \\ USDA-ARS, Manhattan, KS, james.throne@ars.usda.gov \\ Karl J. Kramer \\ USDA-ARS
}

Follow this and additional works at: https://digitalcommons.unl.edu/usdaarsfacpub

Oppert, Brenda; Hammel, Richard; Throne, James E.; and Kramer, Karl J., "Fitness costs of resistance to Bacillus thuringiensis in the Indianmeal moth, Plodia interpunctella" (2000). Publications from USDA-ARS / UNL Faculty. 2008.

https://digitalcommons.unl.edu/usdaarsfacpub/2008

This Article is brought to you for free and open access by the U.S. Department of Agriculture: Agricultural Research Service, Lincoln, Nebraska at DigitalCommons@University of Nebraska - Lincoln. It has been accepted for inclusion in Publications from USDA-ARS / UNL Faculty by an authorized administrator of DigitalCommons@University of Nebraska - Lincoln. 


\title{
Fitness costs of resistance to Bacillus thuringiensis in the Indianmeal moth, Plodia interpunctella
}

\author{
Brenda Oppert, Richard Hammel, James E. Throne \& Karl J. Kramer \\ Grain Marketing and Production Research Center, United States Department of Agriculture, Agricultural Re- \\ search Service, 1515 College Ave., Manhattan, KS 66502, USA (Tel: 785-776-2780; Fax: 785-537-5584; E-mail: \\ bso@ksu.edu)
}

Accepted: May 16, 2000

Key words: fitness, Bacillus thuringiensis, resistance, Plodia interpunctella, Indianmeal moth, resistance management, stored grain, insect, biocontrol

\begin{abstract}
Genetic changes in insects that result in insecticide resistance can also affect their fitness. Here, we report measurements of development time and survival of the Indianmeal moth, Plodia interpunctella (Hübner), to compare the relative fitness of Bacillus thuringiensis (Bt)-susceptible and -resistant colonies. Measurements of larval development time and survival indicated that a fitness cost was associated with resistance to $\mathrm{Bt}$ in some Bt-resistant colonies but not others. Comparisons of geographically different populations revealed inherent differences in development time and survival. In most cases, Bt-resistant moths suffered no disadvantage when feeding on a Bt-treated diet. In many cases, the development of Bt-resistant moths on Bt-treated diet was slower than the unselected moths on untreated diet, but it is unclear whether these differences would affect the successful mating of susceptible and resistant moths.
\end{abstract}

\section{Introduction}

Resistance to the entomopathogen Bacillus thuringiensis $(\mathrm{Bt})$ was first described in field populations of the Indianmeal moth, Plodia interpunctella, collected from grain storage facilities in the midwest (McGaughey, 1985). Since that time, resistance to Bt has been reported in more than a dozen other species of insects in both wild and laboratory-selected populations (Schnepf et al., 1998; McGaughey \& Oppert, 1999). Resistance to insecticides is often accompanied by fitness costs, such as a decreased rate of development, fecundity, survival, or mating competitiveness relative to susceptible insects (Roush \& McKenzie, 1987).

Several studies have previously investigated fitness costs associated with resistance to Bt. There were no differences in fitness between Bt-susceptible and -resistant tobacco budworms, Heliothis virescens, when larvae were fed diets that did not contain $\mathrm{Bt}$ (Gould \& Anderson, 1991). However, there were increases in both development time and mortality for
Bt-resistant tobacco budworm larvae forced to consume Bt. Relative to Bt-susceptible Colorado potato beetles, Leptinotarsa decemlineata, larval development was delayed and egg production was decreased in Bt-resistant beetles feeding on potato plants not treated with Bt (Trisyono \& Whalon, 1997; Alyokhin $\&$ Ferro, 1999). Also, more Bt-susceptible than Btresistant Colorado potato beetles survived after overwintering in diapause (Alyokhin \& Ferro, 1999).

In the diamondback moth, Plutella xylostella, resistance to Bt was correlated with the production of fewer eggs, lower egg hatch, reduced survival, and reduced mating success of males (Groeters et al., 1993, 1994). Reversion to susceptibility to Bt in resistant diamondback moths on untreated diet was associated with an increase in survival (Tabashnik et al., 1994). Because of the lack of fitness in the resistant colony, a rapid decrease in resistant moths in the absence of $\mathrm{Bt}$ was predicted. However, resistance was stable in another colony of Bt-resistant diamondback moths in the absence of selection (Tang et al., 1997). 
A previous study of Bt-susceptible and -resistant Indianmeal moth colonies indicated no differences in development time or larval weight, but a substantial increase in mortality was observed in Bt-resistant colonies reared on diet that did not contain Bt (Johnson \& McGaughey, 1996). Another study reported an increase in development time in moths fed sublethal concentrations of Bt subspecies kurstaki HD-1, and increased concentrations resulted in decreased moth emergence and fertility (Salama et al., 1991). Also in the Indianmeal moth, resistance to another microbial insecticide, a granulosis virus, was associated with lower egg viability, longer development time, and increased adult weight (Boots \& Begon, 1993). Biological parameters may also be affected by the type and moisture content of the diet, as well as temperature of the environment (Johnson et al., 1992).

When selection was discontinued with some of the Bt-resistant Indianmeal moth colonies, resistance to $\mathrm{Bt}$ decreased (McGaughey \& Beeman, 1988). The reversion in at least one colony was proposed to be due to incomplete selection, since the colony had not yet reached a plateau in response to Bt. Resistance in another Bt-resistant colony remained stable after transfer to untreated diet (McGaughey, 1985; McGaughey \& Beeman, 1988). These differences may be due to fitness costs, indicating that fitness should be evaluated for each resistance event.

The success of resistance management of Bt insecticidal toxins may be affected by the relative fitness of resistant versus susceptible insects (Georghiou \& Taylor, 1977; Tabashnik, 1998). In this paper, we compare two fitness parameters, development time and survival, in Bt-susceptible and -resistant Indianmeal moth colonies, and examine differences in Bt-resistant colonies reared on untreated or Bt-treated diets. In addition, we compare these parameters in geographically distinct populations of the Indianmeal moth to ascertain if natural variations are present.

\section{Materials and methods}

Insects used in this study were from three colonies of the Indianmeal moth collected from elevator or farm grain storage: UE343, collected from Enid, OK in 1983; RC688, collected from Riley County, KS in 1988; and FS1092, collected from Medford, OK in 1992 (McGaughey, 1985; McGaughey \& Beeman, 1988; McGaughey \& Johnson, 1992). These parent colonies were reared continuously in the laboratory on a cracked wheat-diet (McGaughey \& Beeman, 1988). Parent colonies were selected for resistance with Bt subspecies kurstaki (HD-1, Dipel ${ }^{\circledR}$, Abbott Laboratories, Chicago, IL), aizawai (HD-112 and HD-133), and entomocidus (HD-198). Formulations were obtained from isolates as previously described (McGaughey \& Johnson, 1992).

Bt-resistant Indianmeal moth colonies were reared on diets containing suspensions of Bt and maintained under continuous selection at doses indicated in Table 1. Bt-susceptible colonies were reared on untreated diet. Bt-susceptible colony UE343 was reared in the laboratory for 20 generations and was the parental colony for resistant colony UE343 HD1(62.5), generated by exposure to $62.5 \mathrm{mg} \mathrm{kg}^{-1} \mathrm{HD}-1$ for 43 generations. HD-1 selection on UE343 HD1(62.5) insects was increased to $500 \mathrm{mg} \mathrm{kg}^{-1}$ after 9 generations of selection at $62.5 \mathrm{mg} / \mathrm{kg}$ and resulted in colony UE343 HD1(500) (data were collected using generation 169). Colony RC688 was maintained for 8 generations in the laboratory prior to selection with HD-1, HD-112, HD-133, HD-198, and HD-1 + HD-133 over 19-24 generations. Colony FS1092 was maintained for 6 generations, and FS1092 HD1 was then selected gradually to a final dose of $500 \mathrm{mg}$ HD-1 per kg diet over 9 generations. A single pair of white-eyed mutants from generation 20 of FS1092 HD1 was used to establish FS1092 WE, which was selected for 82 generations using $2000 \mathrm{mg}$ of $\mathrm{HD}-1$ per $\mathrm{kg}$ diet. $\mathrm{LC}_{50}$ values were obtained for each colony as previously described (McGaughey \& Beeman, 1988).

Bioassays were performed using a cracked wheatdiet (McGaughey \& Beeman, 1988). Resistant colonies were assayed using untreated diet or a diet treated at the maintenance dose indicated for each colony (Table 1). Bt formulations were suspended in $10 \mathrm{ml}$ of deionized water and applied as a slurry to $100 \mathrm{~g}$ of diet. The control diet was treated with $10 \mathrm{ml}$ of water only. The diet treatments were mixed thoroughly and divided equally among three glass jars. Fifty eggs $(\leq 24 \mathrm{~h}$ old $)$ were added to each jar and maintained at $25^{\circ} \mathrm{C}$ and $60 \%$ r.h. Emerging adults were counted daily and removed. The assay was repeated for three consecutive generations.

Data for duration of development and percentage mortality were analyzed using the general linear models procedure (PROC GLM, SAS Institute, 1990). The percentage mortality and mean development time for all insects emerging within a replicate were used in the analysis. Linear contrasts were used for planned mean comparisons (Neter et al., 1990). Variances for 
Table 1. $\mathrm{LD}_{50}$ values of several Bacillus thuringiensis formulations for 12 colonies of the Indianmeal moth, Plodia interpunctella

\begin{tabular}{|c|c|c|c|}
\hline Bt subspecies and strain & $\begin{array}{l}\text { Maintenance concentration } \\
\left(\mathrm{mg} \mathrm{kg}^{-1} \text { diet }\right)\end{array}$ & Colony $^{\mathrm{a}}$ & $\mathrm{LC}_{50}(95 \% \mathrm{CI})^{\mathrm{b}}$ \\
\hline kurstaki HD1 & - & UE343 & $14.4(9.3-22.1)$ \\
\hline kurstaki HD1 & 62.5 & UE343 HD1(62.5) & $1430(1305-1571)$ \\
\hline kurstaki HD1 & 500 & UE343 HD1(500) & $>8000^{\mathrm{c}}$ \\
\hline kurstaki HD1 & - & RC688 & $15.6(14.0-17.4)$ \\
\hline aizawai HD112 & & & $2.7(2.5-3.1)$ \\
\hline aizawai HD133 & & & $2.8(1.4-4.0)$ \\
\hline entomocidus HD198 & & & $6.4(4.3-9.5)$ \\
\hline kurstaki HD1 & 500 & RC688 HD1 & $\sim 5000(1950-40,880)$ \\
\hline aizawai HD112 & 62.5 & RC688 HD112 & $173(150-199)$ \\
\hline aizawai, HD133 & 62.5 & RC688 HD133 & $262(225-312)$ \\
\hline entomocidus, HD198 & 125 & RC688 HD198 & $662(437-1080)$ \\
\hline kurstaki $\mathrm{HD} 1$ + aizawai $\mathrm{HD} 133$ & $62.5 / 62.5$ & RC688 (HD1 + HD133) & $249(228-273)$ \\
\hline kurstaki HD1 & - & FS1092 & $93(65-138)$ \\
\hline kurstaki HD1 & 500 & FS1092 HD1 & Not determined \\
\hline kurstaki HD1 & 2000 & FS1092 WE & $\sim 8000^{\mathrm{d}}$ \\
\hline
\end{tabular}

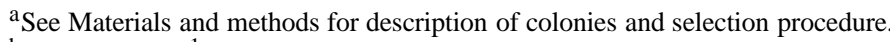

${ }^{\mathrm{b}} \mathrm{Unit}=\mathrm{mg} \mathrm{kg}^{-1}$.

${ }^{\mathrm{c}} 9.5 \%$ mortality obtained at $8000 \mathrm{mg} \mathrm{kg}^{-1}$.

$\mathrm{d}_{58 \%}$ mortality obtained at $8000 \mathrm{mg} \mathrm{kg}^{-1}$.

percentage mortality were not homogeneous, so percentage mortality data were transformed before analysis using the Box-Cox transformation (Box \& Cox, 1964) with $\lambda=3.71$. Means and standard errors for untransformed data are reported.

\section{Results}

The three field-collected colonies of the Indianmeal moth and some corresponding Bt-resistant colonies varied widely in their response to different $\mathrm{Bt}$ formulations (Table 1). Parental colonies UE343 and RC688 were susceptible to HD-1, with $\mathrm{LC}_{50}$ values of approximately $15 \mathrm{mg} \mathrm{kg}^{-1}$. However, FS1092 showed lower susceptibility to HD-1 when the first generation from the field was assayed and has remained approximately 6-fold less susceptible than other fieldcollected colonies. Several 'super-resistant' colonies also were included in the comparison. The levels of resistance in colonies UE343 HD1(500), RC688 HD1, FS1092 HD1 and FS1092 WE were so high that it was not possible to obtain accurate $\mathrm{LC}_{50}$ values.

A comparison of development times and survival for Bt-resistant colonies and their parental colonies revealed some relatively modest fitness costs associated with insect resistance to Bt (Table 2). Development time increased by about one day in the UE343 colony selected at $500 \mathrm{mg} \mathrm{kg}^{-1}$. Similar increases in development times were observed in the HD-112, HD-198, and HD-1 + HD-133-selected RC688 colonies and in the white-eyed mutant FS1092 colony. Survival of the parental colonies ranged from $70-85 \%$. Survival was significantly lower in two of the RC688-resistant colonies, RC688 HD133 and RC688 HD198. Only one resistant colony, RC688 HD198, had both a slower development time and lower survival.

Natural variations in development time and survival of the three parental colonies of Indianmeal moths also were observed (Table 2). Parental colonies RC688 and FS1092 fed untreated diet had significantly longer development times than colony UE343 (linear contrasts, $\mathrm{P}<0.05$ ). Survival of colony FS1092 was lower than for either UE343 or RC688 (linear contrasts, $\mathrm{P}<0.05$ ).

Comparisons of development time and survival among Bt-resistant Indianmeal moth colonies were made (Tables 2 and 3). Comparison of the development times of Bt-resistant colonies feeding on untreated or treated diets revealed that the only delayed development occurred with the white-eyed mutant colony selected from FS1092 HD1, which is a colony maintained with a high dose of Bt (linear contrasts, 
Table 2. Fitness comparison among unselected and Bt-resistant colonies of the Indianmeal moth reared on untreated diet

\begin{tabular}{lllll}
\hline Colony $^{\mathrm{a}}$ & $\begin{array}{l}\text { Development time } \\
\text { (days) }\end{array}$ & $\mathrm{P}^{\mathrm{b}}$ & Percent survival $^{\mathrm{b}}$ & $\mathrm{P}^{\mathrm{c}}$ \\
\hline UE343 & $26.7 \pm 1.3$ & - & $85 \pm 4$ & - \\
UE343 HD1(62.5) & $27.6 \pm 1.1$ & 0.11 & $86 \pm 2$ & 0.78 \\
UE343 HD1(500) & $27.9 \pm 0.1$ & 0.04 & $79 \pm 5$ & 0.13 \\
RC688 & $28.1 \pm 1.2$ & - & $80 \pm 7$ & - \\
RC688 HD1 & $28.1 \pm 0.7$ & 0.89 & $71 \pm 9$ & 0.06 \\
RC688 HD112 & $29.2 \pm 0.9$ & 0.04 & $84 \pm 3$ & 0.39 \\
RC688 HD133 & $28.8 \pm 0.7$ & 0.17 & $65 \pm 4$ & $<0.01$ \\
RC688 HD198 & $29.1 \pm 0.6$ & 0.05 & $48 \pm 15$ & $<0.01$ \\
RC688 (HD1 + HD133) & $29.8 \pm 1.3$ & $<0.01$ & $80 \pm 2$ & 0.76 \\
FS1092 & $28.3 \pm 0.6$ & - & $70 \pm 3$ & - \\
FS1092 HD1 & $29.4 \pm 0.4$ & 0.06 & $58 \pm 17$ & 0.27 \\
FS1092 WE & $29.5 \pm 1.1$ & 0.04 & $66 \pm 7$ & 0.59 \\
\hline
\end{tabular}

${ }^{\text {a }}$ See Materials and methods for description of colonies and selection procedure.

${ }^{\mathrm{b}}$ Mean \pm S.D. $(n=3)$.

${ }^{\mathrm{c}}$ Linear contrasts were used to compare each selected strain with the unselected parent strain.

Contrasts with $\mathrm{P}<0.05$ were significantly different.

$\mathrm{P}<0.05)$. There were no significant differences in the survival of Bt-resistant insect colonies when reared on either untreated or Bt-treated diets. From the Btresistant colonies selected with $500 \mathrm{mg} \mathrm{kg}^{-1}$ of HD-1, FS1092 HD1 had a significantly longer development time and lower survival than UE343 HD1 and RC688 HD1 (Table 3, linear contrasts, $\mathrm{P}<0.05$ ).

Comparisons of development time and survival also were made among unselected Indianmeal moth colonies on untreated diet and Bt-resistant colonies on Bt-treated diet (Table 3). The development times of UE343 HD1(500), RC688 HD112, RC688 HD198, RC688 (HD1 + HD133), FS1092 HD1, and FS1092 WE were significantly longer than their unselected parent colonies. The longest time difference in development was 2.3 days and occurred between FS1092 WE and FS1092. Three colonies, RC688 HD133, RC688 HD198, and RC688 (HD1 + HD133), had significantly lower survival than the unselected parent colonies.

\section{Discussion}

Comparisons between unselected and Bt-resistant Indianmeal moth colonies on untreated diets showed a fitness cost associated with Bt resistance in some colonies but not others (Table 2). However, colonies UE343 HD1(62.5), RC688 HD1, and FS1092 HD1 had neither slower development nor lower survival compared with the parental colonies. Alternatively, colonies UE343 HD1(500), RC688 HD112, RC688 HD198, RC688 HD1 + 133, and FS1092 WE had significantly longer development times. The duration of development was lengthened by 1 to 2 days in resistant colonies. In addition, survival in colonies RC688 HD133 and RC688 HD198 was decreased. At least part of the decreased survival in RC688 HD198 can be attributed to a diminished egg hatch (unpublished observation). Only one of the colonies examined, RC688 HD198, exhibited fitness costs of both longer development time and lower survival.

Some of these data differ from a previous report, in which a significant increase in mortality was associated with nearly all RC688 Bt-resistant colonies (except RC688 HD112) on Bt-untreated diets (Johnson \& McGaughey, 1996). The discrepancy may be due to the level of selection. Whereas resistance ratios varied from 12-30 in the earlier report for the same colonies, they ranged from 27-304 in the present report (corresponding to the $\mathrm{LC}_{50}$ values in Table 1). Resistant strains are maintained on the Bt subspecies used in the selection, and a shift in fitness parameters may indicate an increased adaptation to Bt-treated diets. No differences in larval development time between RC688 susceptible and Bt-resistant colonies reared on untreated diets were reported in the previous 
Table 3. Comparison of unselected Indianmeal moth colonies reared on untreated diets and Bt-selected Indianmeal moth colonies reared on treated diets

\begin{tabular}{lllll}
\hline Colony $^{\mathrm{a}}$ & $\begin{array}{l}\text { Development time } \\
\text { (days) }\end{array}$ & $\mathrm{P}^{\mathrm{c}}$ & Percent survival $^{\mathrm{b}}$ & $\mathrm{P}^{\mathrm{c}}$ \\
\hline UE343 & $26.7 \pm 1.3$ & - & $85 \pm 4$ & - \\
UE343 HD1(62.5) & $27.7 \pm 1.0$ & 0.06 & $84 \pm 0$ & 0.86 \\
UE343 HD1(500) & $28.1 \pm 1.2$ & 0.01 & $79 \pm 13$ & 0.29 \\
RC688 & $28.1 \pm 1.2$ & - & $80 \pm 7$ & - \\
RC688 HD1 & $28.6 \pm 0.7$ & 0.36 & $73 \pm 6$ & 0.10 \\
RC688 HD112 & $29.9 \pm 0.9$ & $<0.01$ & $79 \pm 4$ & 0.59 \\
RC688 HD133 & $28.9 \pm 0.7$ & 0.13 & $61 \pm 5$ & $<0.01$ \\
RC688 HD198 & $29.5 \pm 0.5$ & 0.01 & $47 \pm 14$ & $<0.01$ \\
RC688 (HD1 + HD133) & $29.8 \pm 1.3$ & $<0.01$ & $71 \pm 5$ & 0.04 \\
FS1092 & $28.3 \pm 0.6$ & - & $70 \pm 3$ & - \\
FS1092 HD1 & $30.1 \pm 0.7$ & $<0.01$ & $58 \pm 14$ & 0.21 \\
FS1092 WE & $30.6 \pm 0.9$ & $<0.01$ & $64 \pm 4$ & 0.42 \\
\hline
\end{tabular}

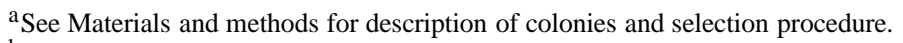

${ }^{b}$ Mean \pm S.D. $(n=3)$.

${ }^{\mathrm{c}}$ Linear contrasts were used to compare each selected strain with the unselected parent strain.

Contrasts with $\mathrm{P}<0.05$ were significantly different.

study, although similar differences in pupation time $( \pm 1.5-2 \mathrm{~d})$ were observed.

Another difference between our study and that of Johnson \& McGaughey (1996) was in the weights of $P$. interpunctella larvae. Johnson \& McGaughey (1996) reported no differences in weights of Btsusceptible and -resistant Indianmeal moths, either as second instars on Bt-untreated diets or fifth instars with susceptible larvae on untreated diets and resistant larvae on Bt-treated diets. Another study found as much as a $47 \%$ reduction in food consumption when Indianmeal moths were fed a Bt-treated diet (AbdelRazek et al., 1999). We observed a substantial variation in larval weight among the colonies, ranging from 8.4 to $12.5 \mathrm{mg}$ for fourth instars (unpublished data). High Bt selection pressure usually resulted in larvae that were larger than those that were not selected or subjected to a low selection pressure. Bt-resistant larvae from UE343 and FS1092 colonies fed Bt-treated diets were $7-12 \%$ larger than larvae from parental colonies fed untreated diet. This size difference may be due in part to a physiological compensation for nutritional stress caused by Bt toxicity. In Bt-resistant strains with increased development time, the increase in larval size may be due to a longer feeding period. It also is possible that the $\mathrm{Bt}$ formulations afforded a nutritional advantage to the diet. Indianmeal moth larvae tended to be larger in the field and decreased in size after being maintained on the artificial diet in the laboratory (unpublished observations). The decrease in size may be a result of a less nutritious artificial diet, increased population density, and/or population genetics.

In most cases, there were no differences in development time and survival due to the consumption of Bt by Bt-resistant Indianmeal moth larvae. When larvae were reared on untreated or Bt-treated diets, a significantly longer development time occurred only with one colony, FS1092 WE, which was selected and maintained on an extremely high dose of HD-1. There were no significant differences in the survival of these colonies when they were fed a Bt-treated diet.

Previously, Dowdy \& McGaughey (1996) used DNA analysis to differentiate six different populations of the Indianmeal moth. A comparison of the three Bt-susceptible colonies from Enid and Medford, Oklahoma and Riley County in Kansas revealed differences in development time and survival, another indication of genetic differences. Insects collected from Enid (UE343) had faster development times, while those collected from Medford (FS1092) had higher mortality. Comparison of Bt-resistant colonies selected from these parental strains with the same dose of HD-1 indicated that the Bt-resistant insects from Medford exhibited a longer development time and decreased survival (Table 2). These results indicate genetic vari- 
ation among these populations and suggest greater problems for the Medford insects on Bt-treated diets.

Both temporal and spatial refugia have been suggested as strategies to slow the development of resistance to Bt (Gould, 1988). Comparisons of the development time of Bt-resistant Indianmeal moths on a Bt-treated diet and unselected Indianmeal moths on untreated diets revealed a lag in development in six of the nine resistant strains examined in this study. A recent report on pink bollworm, Pectinophora gossypiella, indicated that Bt-resistant moths feeding on transgenic Bt-cotton had a longer development time than Bt-susceptible bollworms on non-Bt cotton (Liu et al., 1999). The difference in development times of susceptible larvae on the refuge and resistant survivors on Bt-treated crops could lead to some disruption of the mating of resistant and susceptible moths to dilute the resistance allele(s), a basic tenet of the refuge strategy. The difference in development time of resistant and susceptible pink bollworms was 5.7 days. The largest difference observed with resistant and susceptible Indianmeal moths was 2.3 days. The median longevity of Indianmeal moth adults is approximately 5 days, and most mating occurs within the first day of emergence (unpublished observations). These data suggest that the mating of susceptible and resistant Indianmeal moths would be somewhat diminished by the nonsynchronous development.

A comparison of the composition of the various $\mathrm{Bt}$ formulations yields no information about the differences observed in the selected colonies. Toxins found in HD-198 (Cry1Aa, Cry1Ab, Cry1C, Cry1D) are also found in HD-112 and HD-133, so it appears unlikely that the fitness costs associated with HD-198 are due to its toxin composition. Each of the Bt formulations have at least four different toxins and all contain Cry1 Aa and Cry1 Ab. Whether an individual toxin can induce a specific fitness cost has not been determined. Alternatively, differences observed in the Bt-resistant colonies may be a result of genetic differences among the various colonies.

The physiological cause of high mortality observed in some of the Bt-selected strains is unknown. It is interesting to note that colonies RC688 HD133 and RC688 HD198, which had the lowest survival among the RC688 colonies, lack a major digestive proteinase, and the loss of this proteinase was associated with resistance to Bt (Oppert et al., 1997). However, it is unknown whether the lack of this proteinase is associated with the low survival observed in these colonies.
We conclude that there are modest costs associated with resistance to $\mathrm{Bt}$ in some Indianmeal moth colonies but not in others. However, only several of the many possible fitness parameters were measured in this study, and it is possible that other fitness factors in the Indianmeal moth could be influenced by resistance to Bt. If there is little or no cost, the development of resistance in the Indianmeal moth could be irreversible. The absence of fitness costs may promote the use of alternative Bt-resistance management strategies, such as a multigene strategy with non-overlapping targets, which would be expected to decrease fitness to a greater extent than was observed in this study.

\section{Acknowledgements}

The authors are grateful to Drs. James Campbell, Ralph Howard, Sonny Ramaswamy, and Bruce Tabashnik for critical comments and William McGaughey for helpful discussions. Mention of a proprietary product does not constitute a recommendation or endorsement by the USDA. The USDA is an equal opportunity/affirmative action employer, and all agency services are available without discrimination.

\section{References}

Abdel-Razek, A. S., H. S. Salama, N. D. G. White \& O. N. Morris, 1999. Effect of Bacillus thuringiensis on feeding and energy use by Plodia interpunctella (Lepidoptera: Pyralidae) and Tribolium castaneum (Coleoptera: Tenebrionidae). Canadian Entomologist 131: 433-440.

Alyokhin, A. V. \& D. N. Ferro, 1999. Relative fitness of Colorado potato beetle (Coleoptera: Chrysomelidae) resistant and susceptible to the Bacillus thuringiensis Cry3A toxin. Journal of Economic Entomology 92: 510-515.

Boots, M. \& M. Begon, 1993. Trade-offs with resistance to a granulosis virus in the Indian meal moth, examined by a laboratory evolution experiment. Functional Ecology 7: 528-534.

Box, G. E. P. \& D. R. Cox, 1964. An analysis of transformations. Journal of the Royal Statistical Society 26B: 211-252.

Dowdy, A. K. \& W. H. McGaughey, 1996. Using random amplified polymorphic DNA to differentiate strains of the Indianmeal moth (Lepidoptera: Pyralidae). Environmental Entomology 25: 396400.

Georghiou, G. P. \& C. E. Taylor, 1977. Genetic and biological influences in the evolution of insecticide resistance.Journal of Economic Entomology 70: 319-323.

Gould, F., 1988. Genetic engineering, integrated pest management and the evolution of pests.Trends in Ecology and Evolution 3: 515-518.

Gould, F. \& A. Anderson, 1991. Effects of Bacillus thuringiensis and HD-73 delta-endotoxin on growth, behavior, and fitness of susceptible and toxin-adapted strains of Heliothis virescens (Lepidoptera: Noctuidae). Environmental Entomology 20: 30-38. 
Groeters, F. R., B. E. Tabashnik,, N. Finson \& M. W. Johnson, 1993. Resistance to Bacillus thuringiensis affects mating success of diamondback moth (Lepidoptera: Plutellidae). Journal of Economic Entomology 86: 1035-1039.

Groeters, F. R., B. E. Tabashnik, N. Finson \& M. W. Johnson, 1994. Fitness costs of resistance to Bacillus thuringiensis in the diamondback moth. Evolution 48: 197-201.

Johnson, D. E. \& W. H. McGaughey, 1996. Natural mortality among Indianmeal moth larvae with resistance to Bacillus thuringiensis. Journal of Invertebrate Pathology 68: 170-172.

Johnson, J. A., P. L. Wofford \& L. C. Whitehand, 1992. Effect of diet and temperature on development rates, survival, and reproduction of the Indianmeal moth (Lepidoptera: Pyralidae). Journal of Economic Entomology 85: 561-566.

Liu, Y.-B., B. E. Tabashnik, T. J. Dennehy, A. L. Patin \& A. C. Bartlett, 1999. Development time and resistance to Bt crops. Nature 400: 519.

McGaughey, W. H., 1985. Insect resistance to the biological insecticide Bacillus thuringiensis. Science 229: 193-195.

McGaughey, W. H. \& R. W. Beeman, 1988. Resistance to Bacillus thuringiensis in colonies of Indianmeal moth and almond moth (Lepidoptera: Pyralidae). Journal of Economic Entomology 81: 28-33.

McGaughey, W. H. \& D. E. Johnson, 1992. Indianmeal moth (Lepidoptera: Pyralidae) resistance to different strains and mixtures of Bacillus thuringiensis. Journal of Economic Entomology 85: 1594-1600.

McGaughey, W. H. \& B. Oppert, 1999. Mechanisms of insect resistance to Bacillus thuringiensis toxins. Israel Journal of Entomology 32: 1-14.

Neter, J., W. Wasserman \& M. H. Kutner, 1990. Applied Linear Statistical Models: Regression, Analysis of Variance, and Experimental Designs. Irwin, Homewood, IL.

Oppert, B., K. J. Kramer, R. W. Beeman, D. Johnson \& W. H. McGaughey, 1997. Proteinase-media ted resistance to Bacillus thuringiensis insecticidal toxins. Journal of Biological Chemistry 272: 23473-23476.

Roush, R. T. \& J. A. McKenzie, 1987. Ecological genetics of insecticide and acaricide resistance. Annual Review of Entomology 32: 361-380.

Salama, H. S., R. Aboul-Ela, A. El-Moursy \& A. Abdel-Razek, 1991. Biology and development of some stored grain pests as affected by d-endotoxin and b-exotoxin of Bacillus thuringiensis. Biocontrol Science and Technology 1: 281-287.

SAS Institute, 1990. SAS/STAT ${ }^{\circledR}$ User's Guide, vol. 2, version 6, 4 th ed. SAS Institute, Cary, NC.

Schnepf, E., N. Crickmore, J. Van Rie, D. Lereclus, J. Baum, J. Feitelson, D. R. Zeigler \& D. H. Dean, 1998. Bacillus thuringiensis and its pesticidal crystal proteins. Microbiology and Molecular Biology Reviews 62: 775-806.

Tabashnik, B. E., 1998. Transgenic crops for the Pacific basin: prospects and problems. In: M . P. Zalucki, R. A. I. Drew \& G. G. White, (ed.), Pest Management - Future Challenges, Proc. 6th Australasian Applied Entomology Research Conference, University of Queensland, Brisbane, Vol. 1, pp. 161-168.

Tabashnik, B. E., N. Finson, F. R. Groeters, W. J. Moar, M. W. Johnson, K. Luo \& M. J. Adang, 1994. Reversal of resistance to Bacillus thuringiensis in Plutella xylostella. Proceedings of the National Academy of Sciences of the United States of America 91: 4120-4124.

Tang, J. D., S. Golboa, R. T. Roush \& A. M Shelton, 1997. Inheritance, stability, and lack-of-fitness costs of field-selected resistance to Bacillus thuringiensis in diamondback moths (Lepidoptera: Plutellidae) from Florida. Journal of Economic Entomology 90: 732-741.

Trisyono, A. \& M. E. Whalon, 1997. Fitness costs of resistance to Bacillus thuringiensis in Colorado potato beetle (Coleoptera: Chrysomelidae). Journal of Economic Entomology 90: 267-271. 